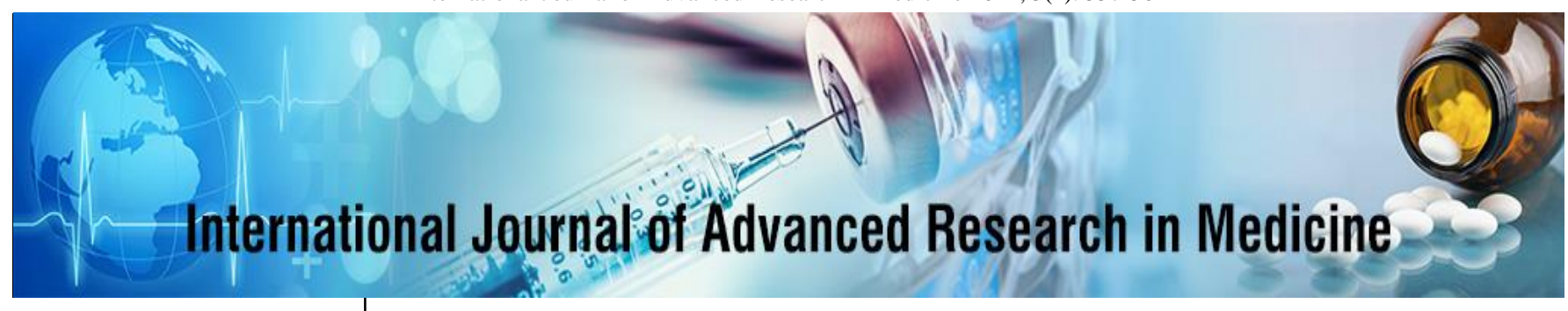

E-ISSN: 2706-9575 P-ISSN: 2706-9567 IJARM 2021; 3(2): 557-562 Received: 07-07-2021 Accepted: 09-09-2021

Dr. Nazima Alauddin Associate Professor, Department of Obstetrics and Gynecology, Institute of Medical Sciences, Chevella, Ranga Reddy, Telangana, India

\footnotetext{
Corresponding Author: Dr. Nazima Alauddin Associate Professor, Department of Obstetrics and Gynecology, Institute of Medical Sciences, Chevella, Ranga Reddy, Telangana, India
}

\section{Effect of pregnancy induced hypertension on clinical course of pregnancy and perinatal outcome}

\author{
Dr. Nazima Alauddin \\ DOI: https://doi.org/10.22271/27069567.2021.v3.i2i.304
}

\begin{abstract}
Background: Pregnancy is a normal physiological process that involves a complex interplay of social, emotional, physiological and anatomical adaptations, which begins soon after fertilization and continues throughout pregnancy. However, a host of medical disorders are known to complicate pregnancy. Hypertensive conditions in pregnancy appear to be one of the major causes of elevated rates of maternal and perinatal mortality and morbidity.

Objective: To know the incidence, etiology, clinical course and fetal outcome of early onset of preeclampsia.

Methods: After obtaining a detail history a thorough examination was carried out. - Laboratory investigations were done as follows: Hemoglobin. Platelet count. Peripheral Blood Smear for Hemolysis, Blood Urea, Serum Creatinine. Scrum Uric Acid, Liver function test, Urine routine examination and microscopy, Fundoscopy. Obstetric Color Doppler. Antiphospholipid antibody syndrome, Non stress Test after 32 weeks. LDH.

Results: In LSCS Emergency was done in 17 patients out of 20 and elective was seen in 3 patients of 20.In Vaginal delivery, Induced was done in 22 patients out of 30 and spontaneous was done in 8 out 30 patients. During Fetal Status, Development of IUGR was seen in $68 \%$ of the cases, Abnormal disorder was seen in $50 \%$ of the cases, IUD was seen in $34 \%$ of the cases, Non Reassuring NST was seen in $32 \%$ of the cases. Birth weight was 1 to $1.5 \mathrm{Kgs}$ was seen in $46 \%$ of the cases, 1.5 to $2 \mathrm{kgs}$ was seen in $16 \%$ of the cases. 2 to $2.5 \mathrm{kgs}$ was seen in $12 \%$ of the cases. In $2 \%$ of the cases birth weight was $>2.5 \mathrm{kgs}$. In outcomes, NICU admission was done in $42 \%$ of the cases, IUD was seen in $34 \%$ of the cases, Early perinatal death $<7$ days was seen in $8 \%$, Termination before 28 weeks happened in $2 \%$ of the cases.

Conclusion: Antenatal care and early registration are the keys to diagnose as well are to treat well in time the cases of early-onset preeclampsia and to refer them to a tertiary center, which offers continuous monitoring and care.
\end{abstract}

Keywords: pre-eclampsia, LSCS, IUGR, IUD, LDH

\section{Introduction}

Pregnancy is a normal physiological process that involves a complex interplay of social, emotional, physiological and anatomical adaptations, which begins soon after fertilization and continues throughout pregnancy. However, a host of medical disorders are known to complicate pregnancy. Hypertensive disorders of pregnancy continue to be one of the leading causes of high rates of maternal and perinatal mortality and morbidity ${ }^{[1]}$.

Preeclampsia of early onset is a distinct entity with devastating consequences. Preeclampsia of early onset may defer from late onset, not only in its very high perinatal morbidity and mortality but in its distinctive maternal risk factors. It has a long term effect like chronic hypertension and patient stands for preeclampsia in her subsequent pregnancy. It is also associated with high pregnancy wastage and perinatal mortality ${ }^{[2]}$.

The etiologies and pathogenesis of early onset preeclampsia like late onset preeclampsia are still obscure. However, it is commonly seen in patients with antiphospholipid antibody syndrome, protein $\mathrm{S}$ deficiency, activated protein $\mathrm{C}$ resistance and hyperhomocysteinaemia leading to endothelial dysfunction. Multiple pregnancy and hydatiform mole also cause early onset pre-eclampsia. The presence of these abnormalities has a definite impact on counseling for future pregnancy and may have an impact on pharmacological management in these pregnancies. Chronic hypertension is a significant risk factor for development of early onset superimposed preeclampsia. The other disorder includes disorders associated with 
endothelial dysfunction such as diabetes, kidney diseases and dyslipidemia. The increased incidence of superimposed preeclampsia in chronic hypertension is explained by the associated preexisting endothelial cell dysfunction ${ }^{[3]}$.

Early onset preeclampsia exhibit features that are unusual as compared to late onset disease. For example, the recurrence risk of preeclampsia is relatively high in women with early onset disease. These women are prone to develop chronic hypertension in their late 30s. The incidence of development of chronic hypertension at early age is one of the complications associated with early onset pre-eclampsia. Fetal growth restriction is much more common and multiorgan involvement, as reflected in 1-IELLP syndrome is more frequent. There is very little difference in the pathogenesis of early and late onset pre-eclampsia. A further classification of these differences is of clinical interest because early onset disease is associated with a higher prevalence of iatrogenic prematurity, IUGR and severe maternal disease ${ }^{[4]}$.

The clinical course of severe early onset preeclampsia may be associated with progressive deterioration in both maternal and fetal condition. As delivery is the only way of arresting the disease, there is a broad agreement on delivery in the presence of multiorgan dysfunction, fetal distress or once 34 weeks of gestation has been reached. However, early onset preeclampsia is an important cause for delivery of very low birth weight babies and delivery at early gestation. There is much controversy regarding the management of early onset of preeclampsia between 24 to 34 weeks of gestation. Many obstetricians recommend immediate delivery and others take a conservative approach, considering prematurity a major risk factor in neonatal outcome. There are still no definitive guidelines as to when and how patients should be treated. But it is important that appropriate treatment in initiated early in patients at high risk and they are closely monitored. Most of the authors have emphasized the lack of uniformity in management approaches to early onset preeclampsia ${ }^{[5,6]}$.

Thus, present prospective study is undertaken to know the incidence, etiology, clinical course and fetal outcome of early onset of preeclampsia.

\section{Material and Method \\ Material}

Number of cases to be studied: 50 cases.

Period of study : from January 2019 to March 2020

\section{Method}

50 cases admitted between 20 weeks to 32 weeks of gestation with PIH were selected for the study.

After obtaining a detail history a thorough examination was carried out. - Laboratory investigations were done as follows:

Hemoglobin. Platelet count. Peripheral Blood Smear for Hemolysis, Blood Urea, Serum Creatinine. Scrum Uric Acid, Liver function test, Urine routine examination and microscopy, Fundoscopy. Obstetric Color Doppler. Antiphospholipid antibody syndrome, Non stress Test after 32 weeks. LDH.

- The cases were treated as per the treatment protocol of preeclampsia

- Investigations will be repeated as an when required.

- Any complication developed during pregnancy-
Intranatal/postnatal due to early onset of preeclampsia were recorded and managed accordingly.

- Perinatal outcome in respect of - a) Still birth b) Live birth - weight of the babies and APGAR score studied.

Ethical Permission: Ethical Clearance was obtained from the institute ethics committee prior to the commencement of the study.

\section{Observation and Results}

Table 1: Age wise distribution of cases, Parity

\begin{tabular}{|c|c|c|}
\hline Maternal Age in yrs & No. of cases & Percentage \\
\hline $18-24$ & 31 & $62 \%$ \\
\hline $25-30$ & 16 & $32 \%$ \\
\hline$>30$ & 3 & $6 \%$ \\
\hline Parity & & \\
\hline Primigravida & 25 & $50 \%$ \\
\hline $2^{\text {nd }}$ Gravida & 8 & $16 \%$ \\
\hline $3^{\text {rd }}$ Gravida & 7 & $14 \%$ \\
\hline Multi Gravida & 9 & $18 \%$ \\
\hline
\end{tabular}

Maximum number of patients around $62 \%$ belonged to the maternal age of 18 to 24 . Primi Gravida was seen in $50 \%$ of the cases, Multi Gravida was seen in $18 \%, 2^{\text {nd }}$ Gravida was seen in $16 \%$ and $3^{\text {rd }}$ Gravida was seen in $14 \%$ of the cases.

Table 2: Gestational age at pr-eclampsia developed

\begin{tabular}{|c|c|c|}
\hline $\begin{array}{c}\text { Gestational Age } \\
\text { (in weeks) }\end{array}$ & $\begin{array}{c}\text { No. of cases with } \\
\text { Pre-Eclampsia }\end{array}$ & Percentage \\
\hline $20-24$ & 8 & $16 \%$ \\
\hline $24-28$ & 13 & $26 \%$ \\
\hline $28-32$ & 19 & $58 \%$ \\
\hline
\end{tabular}

In $58 \%$ of the cases with pre-eclampsia gestational age was 28 to 32 weeks, In $26 \%$ of the cases gestational age was 24 to 28 weeks and in $16 \%$ of the cases gestational age was 20 to 24 weeks.

Table 3: Severity of early onset of Pre-Eclampsia, Associated conditions with early onset of pre-eclampsia, Deterioration of maternal status

\begin{tabular}{|c|c|c|}
\hline Severity of Pre-Eclampsia & $\begin{array}{c}\text { No. of } \\
\text { Cases }\end{array}$ & Percentage \\
\hline Mild & 16 & $32 \%$ \\
\hline Severe & 34 & $68 \%$ \\
\hline Associated Conditions & & \\
\hline Twins & 1 & $2 \%$ \\
\hline APLA Positive & 8 & $16 \%$ \\
\hline SLE Superimposed & 0 & $0 \%$ \\
\hline Thrombophilias & 0 & $0 \%$ \\
\hline Hypothyroidism & 1 & $2 \%$ \\
\hline Impaired GTT & 1 & $2 \%$ \\
\hline Deterioration of maternal & & \\
\hline status & & \\
\hline Premonitory Symptoms & 28 & $56 \%$ \\
\hline RFT/LFT Derangement & 13 & $26 \%$ \\
\hline Thrombocytopenia & 21 & $42 \%$ \\
\hline Hemolysis & 2 & $4 \%$ \\
\hline Ascites & 7 & $14 \%$ \\
\hline Pleural Effusion & 2 & $4 \%$ \\
\hline
\end{tabular}

In $68 \%$ of the cases Severe pre-eclampsia was seen and in $32 \%$ of the cases Mild Pre-eclampsia was observed. 
APLA Positive was seen in $16 \%$ of the cases, Hypothyroidism, Impaired GTT and twins was seen in $2 \%$ of the cases each.

Premonitory symptoms was seen in $56 \%$ of the cases, Thrombocytopenia was seen in $42 \%$ of the cases, RFT/LFT derangement was seen in $26 \%$ of the cases, Ascites was seen in $14 \%$ of the cases. Haemolysis and pleural effusion was seen in $4 \%$ of the cases each.

Table 4: Complications

\begin{tabular}{|c|c|c|}
\hline Complications & No. of cases & Percentage \\
\hline Eclampsia & 8 & $16 \%$ \\
\hline Abruptio Placentae & 4 & $8 \%$ \\
\hline IURG & 34 & $68 \%$ \\
\hline IUD & 17 & $34 \%$ \\
\hline HELLP Syndrome & 2 & $4 \%$ \\
\hline Oligohydramnios & 34 & $68 \%$ \\
\hline Non-Reactive Test & 16 & $38 \%$ \\
\hline PPH & 5 & $10 \%$ \\
\hline
\end{tabular}

Oligohydramnios and IURG complications was seen in $68 \%$ of the cases each, Non-Reactive Test was seen in $38 \%$ of the cases, IUD was seen in $34 \%$ of the cases, Eclampsia was seen in $16 \%$ of the cases, PPH was seen in $10 \%$ of the cases, Abruptio Placentae was seen in $8 \%$ of the cases and HELLP syndrome was seen in $4 \%$ of the cases.

Table 5: Distribution of cases as per time duration between $1^{\text {st }}$ detection and termination

\begin{tabular}{|c|c|c|}
\hline Time duration & No. of cases & Percentage \\
\hline$<24$ Hrs & 5 & $10 \%$ \\
\hline $48-72$ Hrs & 2 & $4 \%$ \\
\hline $4-7$ Days & 10 & $20 \%$ \\
\hline $1-2$ weeks & 15 & $30 \%$ \\
\hline $2-4$ weeks & 10 & $20 \%$ \\
\hline$>4$ weeks & 8 & $16 \%$ \\
\hline
\end{tabular}

In time duration between $1^{\text {st }}$ detection and termination, In $30 \%$ of the cases time duration was 1 to 2 weeks, In $20 \%$ of the cases each Time duration was 4 to 7 days and 2 to 4 weeks. In $16 \%$ of the cases time duration was $>4$ weeks, In $10 \%$ of the cases time duration was $<24 \mathrm{hrs}$, In $4 \%$ of the cases time duration was 48 to $72 \mathrm{hrs}$ between detection and termination.

Table 6: Termination of pregnancy as per the gestational age

\begin{tabular}{|c|c|c|}
\hline Gestational Age & No. of cases & Percentage \\
\hline$<28$ weeks & 4 & $8 \%$ \\
\hline $28-32$ weeks & 21 & $42 \%$ \\
\hline $32-34$ weeks & 19 & $38 \%$ \\
\hline $34-37$ weeks & 2 & $4 \%$ \\
\hline$>37$ weeks & 4 & $8 \%$ \\
\hline
\end{tabular}

In $42 \%$ of the cases gestational age was between 28 to 32 weeks, In $38 \%$ of the cases, gestational age was between 32 to 34 weeks, In $8 \%$ of the cases each gestational age was $<28$ weeks or $>37$ weeks. In $4 \%$ of the cases gestational age was 34 to 37 weeks.

Table 7: Mode of delivery

\begin{tabular}{|c|c|c|c|}
\hline LSCS & Elective & Emergency & Total \\
\hline No. of cases & 3 & 17 & 20 \\
\hline Vaginal Delivery & Induced & Spontaneous & Total \\
\hline No. of cases & 22 & 8 & 30 \\
\hline
\end{tabular}

In LSCS Emergency was done in 17 patients out of 20 and elective was seen in 3 patients of 20.

In Vaginal delivery, Induced was done in 22 patients out of 30 and spontaneous was done in 8 out 30 patients.

Table 8: Deterioration of fetal cases

\begin{tabular}{|c|c|c|}
\hline Fetal Status & No. of cases & Percentage \\
\hline Development of IUGR & 34 & $68 \%$ \\
\hline Abnormal disorder & 25 & $50 \%$ \\
\hline IUD & 17 & $34 \%$ \\
\hline Non Reassuring NST & 16 & $32 \%$ \\
\hline
\end{tabular}

During Fetal Status, Development of IUGR was seen in $68 \%$ of the cases, Abnormal disorder was seen in $50 \%$ of the cases, IUD was seen in $34 \%$ of the cases, Non Reassuring NST was seen in $32 \%$ of the cases.

Table 9: Birth Weight

\begin{tabular}{|c|c|c|}
\hline Birth Weight & No. of cases & Percentage \\
\hline$<1 \mathrm{Kg}$ & 12 & $24 \%$ \\
\hline $1-1.5 \mathrm{Kgs}$ & 23 & $46 \%$ \\
\hline $1.5-2 \mathrm{Kgs}$ & 8 & $16 \%$ \\
\hline $2-2.5 \mathrm{Kgs}$ & 6 & $12 \%$ \\
\hline$>2.5 \mathrm{kgs}$ & 1 & $2 \%$ \\
\hline
\end{tabular}

Birth weight was 1 to $1.5 \mathrm{Kgs}$ was seen in $46 \%$ of the cases, 1.5 to $2 \mathrm{kgs}$ was seen in $16 \%$ of the cases. 2 to $2.5 \mathrm{kgs}$ was seen in $12 \%$ of the cases. In $2 \%$ of the cases birth weight was $>2.5 \mathrm{kgs}$.

Table 10: Perinatal outcome

\begin{tabular}{|c|c|c|}
\hline Outcome & No. of cases & Percentage \\
\hline Termination before 28 weeks & 1 & $2 \%$ \\
\hline IUD & 17 & $34 \%$ \\
\hline NICU Admission & 21 & $42 \%$ \\
\hline Early perinatal death <7days & 4 & $8 \%$ \\
\hline Late perinatal days & 0 & $0 \%$ \\
\hline Congenital Anomaly & 0 & $0 \%$ \\
\hline
\end{tabular}

In outcomes, NICU admission was done in $42 \%$ of the cases, IUD was seen in $34 \%$ of the cases, Early perinatal death $<7$ days was seen in $8 \%$, Termination before 28 weeks happened in $2 \%$ of the cases

\section{Discussion}

Early onset pre-eclampsia is associated with high maternal and perinatal morbidity and mortality. Expectant management of early onset severe pre-eclampsia and careful neonatal care led to high perinatal and neonatal survival rate but it does poses the mother to great risk. In this study the following factors in cases of early onset pre-eclampsia were studied

- Incidence

- Possible factors responsible for early onset preeclampsia

- Clinical course

- Outcome

\section{Incidence}

Incidence of early onset preeclampsia of all preeclampsia diagnosed. $20 \% 13.4 \%$ onset preeclampsia was $2.9 \%$ of In present study the incidence of early all antenatal cases and $20 \%$ of all preeclampsia diagnosed which was done by Liu Q et al. ${ }^{[8]}$ in China where the more in comparison to a study 
cases of early onset preeclampsia accounted for $13.4 \%$ of all another study Murphy et al. ${ }^{[7]}$ pre-eclampsia diagnosed and in united Kingdom reported the incidence of early onset preeclampsia as 1 in 682 births which was less than our study. As both the studies were done at different geographical locations and the study population were also different and hence the differences could be due to geographical and genetic variations. This could also be due to poor nutritional status of the women and lack of awareness regarding availing antenatal care early or pre pregnancy consultation. Majority of the cases were Primi gravida but also a significant number were of higher birth order reflecting a probability of immunological factor as a cause. $16 \%$ patients had very early onset PIH as early as 2024 weeks of gestation. All these patients had severe preeclampsia which had led to increased maternal complications and as well fetal compromise in the form of intrauterine death.

Possible Factors Responsible For Early Onset Pre-Eclampsia

\begin{tabular}{|c|c|}
\hline & APLA Positive \\
\hline Present study & $16 \%$ \\
\hline Moodley et al & $11.7 \%$ \\
\hline Dekker et al & $16-20 \%$ \\
\hline
\end{tabular}

In our study $16 \%$ of the patients were APLA positive which is comparable with the study carried out by Dekker et al. in $1995^{9}$ which found that at least $16 \%$ to $20 \%$ of patients with a history of early onset preeclampsia have elevated ACA levels and hence concluded that patients with a history of severe early onset preeclampsia should be screened for protein $\mathrm{S}$ deficiency, activated protein $\mathrm{C}$ resistance, hyperhomocysteinemia and anticardiolipin antibodies. Similar results were given by Szilagyi et al, Kobayashi et al Bloomenthal et al and Lockwood et al, Branch et al found an association of $16 \%$ between antiphospholipid antibodies and early onset pre-eclampsia but have described no cases before 25 weeks of gestation. Dekker et al in 1995 found no positive cases of lupus anticoagulant in their study on early onset pre-eclampsia and the same result were found in our study.

In this study $42 \%$ of the patients were observed to have thrombocytopenia, whether as a cause or the effect of early onset preeclampsia is still obscure. Further investigations needed to rule out thrombophilia's as a cause of low platelet count or any other immunological disorder or any other viral conditions like Dengue, Malaria which is very common in our country. But our results are consistent with results of Heilmann L et al (2007) who concluded that there is lowering of platelet count in severe early onset preeclampsia, and these subgroups of women have severe hematological abnormalities than women with late preeclampsia.

Hypothyroidism and deranged GTT were associated in 2\% of the patients which indicates it has no significant correlation in the development of pre-eclampsia. In this study no cases due to hydatidiform mole, fetoplacental triploidy with partial mole changes and idiopathic hydrops fetalis were done by Vatish et al seen in contrast with other studies like study concluded that triploidy/ diploid mosaicism was diagnosed following karyotyping of an infant with musculoskeletal abnormalities delivered of severe pre-eclampsia. An area of placenta appeared unusual with history suggestive of trophoblastic abnormality. The importance of detailed histological examination and ploidy and flow cytometry studies where diagnostic uncertainty exists are highlighted. Giannattasio et al. Mutation reported the combination of fetal triploidy and early onset preeclampsia and Broekhuizen et al concluded that early onset preeclampsia is frequently associated with fetal and placental anomalies. Hydatidiform mole. fetoplacental triploidy with partial molar changes and idiopathic fetalis are commonly associated with early onset pre-eclampsia. $72 \%$ of the Cases of early onset preeclampsia in their institute were associated with significant fetal and placental malformations. An immunological basis of the preeclampsia in these cases seems unlikely.

Lack of facility for Karyotyping of the fetal and placental tissue, as patients were from very low socio economic strata so it was not possible to send placenta or cord blood for karyotyping on account of cost, and a small sample size did not reveal this as an etiological factor in this study.

Clinical Course Of The Disease In $58 \%$ of present study group the onset of pre-eclampsia was detected for the first time at 28-32 weeks of gestation and in $26 \%$ the onset was between 24-28 weeks of gestation, thus it is seen that majority of present cases had their onset towards the end of midtrimester and beginning of third trimester and that is why most of the studies have included 32 weeks and 34 weeks as cut off period of gestation for the early onset preeclampsia in their definition. Present results are Comparable with various studies done by Onah et al, [10] Alsulyman et al ${ }^{[11]}$ Where onset of preeclampsia is seen in less than 30 weeks of gestation and also with various studies done by Jose Villar et al ${ }^{[12]}$, Dekker GA et al ${ }^{[13]}$ where the onset was seen at less than 32 weeks of gestation. W.ere rpf the patients developed eclampsia and all these patients 16 of referred to our hospital from outside for further management. In present study group $32 \%$ had mild early onset of preeclampsia while $68 \%$ had severe onset of preeclampsia. Expectant management was instituted in all cases of severe preeclampsia with detonation of maternal and fetal condition leading to termination of pregnancy and birth of a present study rate of various maternal complications are Prete $^{\circ}$ baby. In $\%$ of the patients developed premonitory signs and as follows 56 ry symptoms, $42 \%$ had thrombocytopenia, $26 \%$ had renal function or liver function test derangement, $68 \%$ had intrauterine growth restriction, $34 \%$ had intrauterine fetal demise, $4 \%$ had HELLP syndrome, 14\% had ascites, 4\% had pleural effusion, $68 \%$ had oligohydramnios. There was no maternal death. The increased rate of intrauterine demise is attributed to late antenatal registration and poor compliance of the patients. The rate of abruption was $8 \%$.

It is being observed that raised LDH levels and low platelet count as an indicator of severe form of pre-eclampsia. $\mathrm{LDH}$ is an early marker of haemolysis so the patients with HELLP syndrome could be diagnosed early and treated. Classification of HELLP Syndrome 
Table 11: Mississippi vs Tennessee classification

\begin{tabular}{|c|c|}
\hline Mississippi classification & Tennessee classification \\
\hline $\begin{array}{l}\text { Class } 1: \\
\text { - Platelets }<50,000 \\
\text { - MT or ALT }>70 \mathrm{IU} / \mathrm{L} \\
\text { - } \mathrm{LDH}>600 \mathrm{IU} / \mathrm{L} \\
\end{array}$ & $\begin{array}{l}\text { True or Complete } \\
\text { - Platelets }<100,000 \\
\text { - AST }>701 \mathrm{U} / \mathrm{L} \\
\text { - } \mathrm{LDH}>600 \mathrm{IU} / \mathrm{L} \\
\end{array}$ \\
\hline $\begin{array}{l}\text { Class 2: } \\
\text { - Platelets }=50,000-100,000 \\
\text { - AST or ALT }>70 \mathrm{IU} / \mathrm{L} \\
\text { - } \mathrm{LDH}>600 \mathrm{IU} / \mathrm{L}\end{array}$ & $\begin{array}{l}\text { Partial or incomplete } \\
\text { Severe preeclampsia, with either of the following: } \\
\text { ELLP, EL, HEL, LP }\end{array}$ \\
\hline $\begin{array}{l}\text { Class 3: } \\
\text { - Platelets }=100,000-150,000 \\
\text { - AST or ALT }>40 \mathrm{IU} / \mathrm{L} \\
\text { - } \text { LDH }>600 \mathrm{IU} / \mathrm{L}\end{array}$ & \\
\hline
\end{tabular}

There was no maternal death in present study which is similar to the study done by Hall et al. ${ }^{[14]}$ This is also due to timely intervention and level of care we can offer.

The average prolongation of gestation that could be achieved after detection or presentation of the case was 14 days which is similar to the study done by Sibai et al. ${ }^{[15]}$ In Hall D R et al. ${ }^{[16]}$ study the pregnancies were prolonged by a mean number of 11 days. In another study of Oettle $\mathrm{C}$ et al the average prolongation of gestation was 11.6 days. In a study of Murphy DJ et al..$^{7}$ on early onset preeclampsia the mean diagnosis to delivery interval was 14 days

Table 12: Average prolongation of gestation - Previous studies

\begin{tabular}{|c|c|}
\hline & Average prolongation of gestation \\
\hline Present study & 14 days. \\
\hline Sibai et al. & 14 days \\
\hline Hall D R et al. & 11 days \\
\hline Oettle C et al. & 11.6 days \\
\hline
\end{tabular}

In this study mode of delivery was caesarean section in $40 \%$ of the cases out of which majority of them were done on an emergency basis. Emergency LSCS was done for fetal distress, abruption, deterioration of maternal condition and development of imminent signs of eclampsia.

$60 \%$ of the patients delivered vaginally and majority of them were extremely preterm vaginal deliveries, only $12 \%$ of the patients could reach up to term pregnancy and these had mild pre-eclampsia. Vaginal birth was allowed in all intrauterine death and patients who had good Bishop's Score.

OUTCOME Out of 50 babies delivered, 17 were intrauterine death. The mean birth weight was 1380 gms which is comparable with Hall et al where they had a mean birth weight of $1400 \mathrm{gms}$, and different with the C. Oettle et $a l$ where they had a mean birth weight of 1624 gms.

Table 13: Mean birth weight of neonate - previous study

\begin{tabular}{|c|c|}
\hline & Mean Birth Weight of the neonate \\
\hline Our study & $1380 \mathrm{gms}$. \\
\hline Hall et al & $1400 \mathrm{gms}$ \\
\hline C. Oettle et al & $1624 \mathrm{gms}$ \\
\hline
\end{tabular}

As maximum number of patients delivered between 28-34 weeks of gestation, so it was prematurity which was the cause of low birth weight and N1CU admissions.

Perinatal mortality rate in this study was 63/1000 live births.

\section{Conclusion}

In this study perinatal mortality was very high because patients were from very low socio-economic status not affording the care provided in a tertiary care center, so did not take treatment as advised and did not get admitted to the hospital as an when asked. Thus, the study concludes, the importance of antenatal visits, early detection and treatment, and the minimal role of expectant management in prolonging the pregnancy to improve perinatal outcome. Antenatal care and early registration are the keys to diagnose as well are to treat well in time the cases of earlyonset preeclampsia and to refer them to a tertiary center, which offers continuous monitoring and care.

\section{References}

1. Lain KY, Roberts JM. Contemporary concepts of the pathogenesis and management of preeclampsia. JAMA. 2002;287:3183- 6 .

2. Chesley LC. History and epidemiology of preeclampsia-eclampsia. Clin obstet Gynecol. 1984;27:801-20.

3. Sibai B, Dekker G, Kupfermine M. Preeclampsia. Lancet. 2005;365:785-99.

4. Witlin AG, Saade GR, Manor F, Sibai BM. Predictors of neonatal outcome in women with severe preeclampsia or eclampsia between 24 and 33 weeks gestation. Am J Obstet Gynecol. 2000;182:607-

5. Lie RT, Rasmussen S, Brunborg H, Gjessing HK. Lie Nielsen E, Irgens LM. Fetal and maternal contribution to risk of preeclampsia: Population based study. BMJ. 1998;316:1343-7.

6. Sibai BM, Mercer B, Sarinoglu C. Severe preeclampsia in the second trimester: recurrence risk and long term prognosis. Ate J Obstet Gynecol. 1991;165:1408-12.

7. Murphy DJ, Stirrat GM. Mortality and Morbidity associated with early - onset preeclampsia. Hypertens Pregnancy. 2000;19(2):221-31.

8. Liu Q, He J, Dong MY, Lou ZX Clinical features and prognosis of early onset preeclampsia. Zhejiang Da XueXue Bao Yi Xue Ban. 2005;34(6):506-9.

9. Deldcer GA, Doelitzsch PM, Huijgens PC, Von Blomberg BME, Van Geijin HP. Underlying disorder associated with Jacobs C, necol 1995;173: severe early onset preeclampsia. Am J Obstet Gy 1042-8.

10. Onah HE, Iloabachie GC. Conservative management of early-onset pre-eclampsia and fetomaternal outcome in Nigerians. J Obstet Gynaecol. 2002;22(4):357-62.

11. Alsulyman OM, Castro MA, Zuckerman E, McGehee W, Goodwin TM. Preeclampsia and liver infarction in early pregnancy associated with the antiphospholipid syndrome. Obstet Gynecol. 1996;88(4 pt2):644-6. 
12. Jose Villar M D. World Health Organization randomized trial of calcium supplementation among low calcium intake pregnant women. Am J Obstet Gynecol. 2006;194:639-49.

13. Dekker GA. The pharmacological prevention of preeclampsia. Baillieres Clin Obstet Gynaecol. 1995;9(3):509-28.

14. Hall DR, Odendaal HJ, Steyn DW, Grove D. Expectant management of early onset, severe preeclampsia; maternal outcome. BJOG. 2000;107(10):1252-7.

15. Bolte AC, Van Eyck J, Kanhai HH, Bruinse HW, Van Geijn HP, Dekker GA. Ketanserin versus dihydralazine in the management of severe early - onset preeclampsia: maternal outcome. Am J Obstet Gynecol. 1999;180(2Pt1):371-7.

16. Hall DR, Odendaal HJ, Steyn DW, Grove D. Expectant management of early onset, severe preeclampsia; maternal 